\title{
La propiedad de uno mismo: alcances y límites en la filosofía política de G.A. Cohen
}

Karl Palomino Flores

Pontificia Universidad Católica del Perú

Resumen: Este texto propone una defensa de la crítica que Cohen realiza al concepto de propiedad de uno mismo. Para ello, presentaremos la crítica de Cohen a dicho concepto en la obra de Nozick. Luego, se expondrá la defensa elaborada por Mack de la propiedad de uno mismo en la obra de Nozick, por medio de la formulación de lo que denomina "cláusula de propiedad de uno mismo". Por último, se sostendrá que dicha cláusula no permite superar las críticas de Cohen, debido a que su cumplimiento es compatible con un régimen de propiedad colectiva.

Palabras clave: G.A. Cohen, Nozick, propiedad de uno mismo, propiedad privada, libertad

Abstract: "Self-Ownership: scope and limits in the political philosophy of G.A. Cohen". This paper proposes a defense of Cohen's critique of the concept of self-ownership. In order to do so, we will present Cohen's critique of this concept in Nozick's work. Secondly, we will present Mack's defense of self-ownership in Nozick's work through the formulation of what he will call the "self-ownership proviso". Finally, we will argue that such proviso does not allow us to overcome Cohen's criticisms because its compliance is compatible with a collective property regime.

Keywords: G.A. Cohen, Nozick, self-ownership, private property, freedom 


\section{§1. Introducción}

Dentro de los exponentes del llamado marxismo analítico, G.A. Cohen resalta como una de las figuras más representativas de dicho movimiento. Entre sus obras más importantes se encuentra Self-Ownership, Freedom, and Equality (1995), que elabora de manera detallada una crítica a la propuesta libertaria de Robert Nozick en su famoso libro Anarquía, Estado y utopía (1988). La crítica de Cohen busca defender que el libertarianismo es incapaz de ofrecer tanto una teoría de la justicia aceptable como una propuesta moralmente consistente sobre la libertad. Enfoca, así, parte importante de su crítica en evaluar la pertinencia del concepto libertario de propiedad de uno mismo (self-ownership). Siendo el libro de Nozick uno de los baluartes en la defensa del capitalismo libertario, ha corrido mucha tinta intentando impugnar la crítica de Cohen'. Dentro de dichos intentos, uno de los más interesantes es el elaborado por Eric Mack en su artículo "Self-Ownership, Marxism, and Egalitarianism" (2002).

El objetivo de este artículo es ofrecer una reconstrucción de la crítica de Cohen a la noción de propiedad de uno mismo, explicando el entrampamiento al que lleva a la propuesta de Nozick. Posteriormente se desarrollará la crítica de Mack a Cohen, quien al añadir una cláusula de propiedad de uno mismo más fuerte que la de Nozick, parece forzar a Cohen a rechazar el igualitarismo y a preferir una sociedad que tenga a la propiedad privada como base. En la última sección del artículo, se exploran los alcances de dicha crítica y se concluye que la propuesta de Cohen no solo no sucumbe ante las críticas de Mack, sino que, además, esta encuentra en dichas críticas elementos relevantes para brindar una justificación de una sociedad gobernada por un principio de igualdad.

1 Para otras críticas a la propuesta de Cohen, pueden revisarse los artículos de Jan Narveson (1998) y George Brenkert (1998). Para una respuesta de Cohen a dichas objeciones revisar: Once More into the Breach of Self-Ownership: Reply to Narveson and Brenkert (1998). 


\section{§2. La crítica de G.A Cohen a la propiedad de uno mismo}

En el desarrollo de la propuesta libertaria de Nozick se encuentra una justificación del Estado mínimo como el único Estado legítimo. La primera parte de dicha obra se enfoca en brindar una justificación del Estado mínimo, y es la segunda parte en donde se establece que cualquier Estado que pretenda tener mayores atribuciones que las de un Estado mínimo será un Estado ilegítimo, pues violaría los derechos de sus miembros (Nozick 1988, 7). Para alcanzar su objetivo, Nozick argumenta que los derechos de propiedad son naturales y que su defensa es central para la legitimidad de un Estado; de modo que cualquier pauta que pretenda establecer una distribución de los bienes del Estado que exceda el terreno de las transacciones voluntarias sería ilegítima moralmente $(1988,162)$. Nozick, por tanto, se compromete a ofrecer una teoría que explique la legitimidad de la propiedad privada, proyecto que tiene lugar en el transcurso de la primera parte del capítulo VII de Anarquía, Estado y utopía y que, según Cohen, necesita apelar a un concepto clave que es la noción de propiedad de uno mismo (self-ownership) (Cohen 1995, 65).

Cohen criticará dos aspectos clave de la teoría de Nozick: primero, que el libertarianismo debe ofrecer una justificación de la propiedad privada en términos de una noción diferente a la de libertad $(1995,61)$; segundo, que el principio de propiedad de uno mismo no es capaz de brindar dicha justificación (1995, 67-91).

Cohen inicia su crítica contra la propuesta libertaria atacando la idea de que cualquier pauta distributiva en una sociedad vulnera la libertad de los propietarios. Según el libertarianismo, si una persona por medio de sus talentos ha logrado acumular una cantidad amplia de bienes, el hecho de que el Estado establezca una medida redistributiva afectaría la libertad de dicha persona $(1995,55)$. Cohen identifica en este punto una idea problemática, y es que el motivo por el cual podemos hablar de una restricción de la libertad en dicho caso es porque que hay una restricción a las acciones disponibles para la persona. Cohen señala que una sociedad carente de pautas distributivas tiene un marco normativo que también establece límites a las acciones de las personas que carecen de propiedad. Por ejemplo, si 
una persona pone una carpa en el patio de su vecino, puede ser expulsado de dicho patio por la policía si es que el vecino así lo solicita $(1995,56)$. Cohen sostiene que si la noción de libertad solo consiste en la capacidad de actuar sin interferencia, estas restricciones a la acción estarán presentes tanto en una sociedad con pautas distributivas como en una sociedad sin ellas $(1995,56)$. Dado que la libertad en ambas sociedades se ve restringida, sostener que la propiedad privada se legitima en virtud de la libertad que promueve en los miembros de la sociedad es insuficiente.

El libertario puede responder que hay una inmensa diferencia entre la restricción a la acción acontecida en el caso de la carpa y la que ocurre cuando se imponen pautas distributivas en la sociedad. Mientras que la persona que es desalojada del patio del vecino no tiene derecho a poner su carpa en él, la persona que es gravada con impuestos o a la que el Estado expropia parte de sus bienes sí tiene derecho a estos; por lo cual, la crítica de Cohen no logra poner en tela de juicio la postura libertaria $(1995,59)$. Cohen señala que dicha respuesta se compromete con una noción diferente de libertad, a la que llama "definición de derechos de libertad" (1995, 59)2; según esta hay una vulneración a la libertad de las personas solo si se le impide a una persona hacer algo que tiene derecho a hacer. Por lo cual, la protección de la propiedad privada no restringe la libertad de nadie $(1995,56)$. Asimismo, argumenta que esta respuesta debe explicar cómo el propietario llega a tener derechos morales sobre su propiedad privada. Si el libertario justifica dichos derechos morales apelando a la libertad, entonces

2 Cohen realiza la reconstrucción de dicha definición de libertad tomando como referencia la siguiente cita de Nozick: "Que las acciones de una persona sean voluntarias depende de lo que limita sus alternativas. Si los hechos de la naturaleza lo hacen, las acciones son voluntarias. (Puedo voluntariamente caminar hasta algún lugar al que yo preferiría volar sin ninguna ayuda.) Las acciones de otras personas ponen límites a las oportunidades disponibles de uno. Si esto hace la acción no voluntaria, depende de si los otros tienen derecho de actuar como lo hicieron" (1988, 255; cursivas añadidas). La cita de Nozick busca introducir la discusión respecto a qué tan voluntaria puede ser una acción en casos en los cuales las personas tienen marcos muy reducidos de acción, fruto del ejercicio de la libertad de los demás. Esta idea se articula de manera clara con el proyecto general de su propia teoría de la justicia: "(1) Una persona que adquiere una pertenencia, de conformidad con el principio de justicia en la adquisición, tiene derecho a esa pertenencia. (2) Una persona que adquiere una pertenencia de conformidad con el principio de justicia en la transferencia, de algún otro con derecho a la pertenencia tiene derecho a la pertenencia. (3) Nadie tiene derecho a una pertenencia excepto por aplicaciones (repetidas) de 1 y 2" (1988, 154; cursivas añadidas). 
cae en un círculo, pues la libertad era justamente lo que se buscaba definir a partir de los derechos morales sobre la propiedad. En caso el libertario pretenda justificar la definición de derechos de libertad apelando a la noción de libertad inicial (ausencia de restricciones a la acción), entonces vuelve al problema inicial de la carpa en el terreno del vecino $(1995,60)$. Por todo ello, el libertario debe ofrecer una justificación de la propiedad que no apele a la noción de libertad, y Cohen reconoce que la obra de Nozick pretende superar dicha problemática apelando a la noción de propiedad de uno mismo (1995, 65-66).

Al desarrollar su ataque a la propiedad de uno mismo, Cohen toma dos rutas: por un lado, establece que esta no es capaz de brindar una legitimación eficiente de la propiedad privada3; por otro lado, y este es el núcleo de la crítica de Cohen al libertarianismo de Nozick, señalará que dicha noción está igualmente ausente o presente tanto en sociedades con pautas distributivas como en sociedades sin estas; por lo cual es incapaz de legitimar un tipo específico de régimen de propiedad ${ }^{4}$.

Para entender la crítica de Cohen, tomemos la siguiente definición de la propiedad de uno mismo que plantea en Self-Ownership, Freedom and Equality:

Propiedad de uno mismo (self-ownership): “Cada persona es el dueño moralmente legítimo de su propia persona y poderes $y$, en consecuencia, cada uno es libre (moralmente hablando) de usar esos poderes como lo desee, siempre que no los despliegue agresivamente contra otros" (1995, 67; la traducción es mía).

Es evidente que el principio de propiedad de uno mismo no es suficiente para explicar la legitimidad de la propiedad privada. El hecho de que alguien emplee sus capacidades y su propio cuerpo en la obtención de un bien no explica por qué no entender la apropiación como un robo de

3 Este será el objetivo de todo el capítulo 3 de Self-Ownership, Freedom and Equality.

4 Este será el objetivo de todo el capítulo 4 de Self-Ownership, Freedom and Equality. 
aquello que ha de ser poseído en común ${ }^{5}$ por todas las personas; como agudamente denuncia Rousseau ya en el siglo XVIII ${ }^{6}$. Por ello, es necesaria una teoría de la adquisición que tome como elemento adicional las condiciones legítimas para la apropiación, de modo tal que si dichas condiciones se han cumplido, la propiedad obtenida no puede ser objeto de eventual redistribución. La idea es que si se ha obtenido un bien por medio de un procedimiento de apropiación justo, toda transferencia voluntaria del bien mismo preservará la justicia, sin importar las desigualdades que eventualmente podrían generarse fruto de los intercambios eventuales (Nozick 1988, 154-155).

Tomando como hipótesis la ausencia de propiedad privada, uno entiende que en dicho contexto es intuitivo que las personas puedan apropiarse de diferentes bienes para su propio beneficio. Evidentemente el proceso de apropiación no puede ser irrestricto, pues dejaría sin capacidad de poder disfrutar de dichos bienes a los demás habitantes del mundo. Argumentar que uno merece una primacía sobre un determinado bien, dado que fue el primero en llegar no resulta suficientemente persuasivo, pues nadie puede ser responsabilizado por algo que no estuvo al alcance de su elección, ya que nadie elige el tiempo y lugar en el que nace ${ }^{7}$. Es por ello que Nozick

5 Se podría objetar que ningún libertario tiene por qué aceptar dicha alternativa. Pero en el desarrollo de la objeción presentada en Self-Ownership, Freedom and Equality, Cohen solo necesita sostener que no hay un derecho de apropiación obvio que sea indiferente a la exigencia del consentimiento ajeno. Basta la posibilidad de comprender al mundo como un bien poseído en común para que los demás puedan poner objeciones al proceso de apropiación. En ese sentido, si el libertario desea sostener su postura, necesita considerar dicha alternativa como insostenible. Ahora bien, es importante resaltar que la consideración respecto al mundo como propiedad común es una consideración de naturaleza moral. Para una respuesta de Cohen más detallada respecto a la comprensión del mundo como originariamente poseído en común, revisar: Once More into the Breach of Self-Ownership: Reply to Narveson and Brenkert (1998).

6 La siguiente cita del Discurso sobre el origen y el fundamento de la desigualdad entre los hombres captura dicha idea: "El primero a quien, tras haber cercado un terreno, se le ocurrió decir: 'Esto es mío', y encontró personas lo bastante simples para creerle, fue el verdadero fundador de la sociedad civil. Cuántos crímenes, guerras, asesinatos; cuántas miserias y horrores habría ahorrado al género humano el que, arrancando las estacas o cegando el foso, hubiera gritado a sus semejantes: '¡Guardaos de escuchar a ese impostor; estáis perdidos si olvidáis que los frutos son de todos y la tierra no es de nadie!"' (Rousseau 2012, 171).

7 Vale la pena tener en cuenta la poca importancia que le confiere Nozick al problema del azar, que autores como Rawls (1979) y Cohen (2008) sí se detienen a considerar como fundamental para poder hablar de una sociedad justa. 
es consciente de que se requiere un elemento adicional que justifique la apropiación. A diferencia de Locke y su teoría del trabajo, la cual considera insuficiente para brindar una justificación de la propiedad de bienes externos $(1988,176)$, Nozick sostiene que debe cumplirse la siguiente cláusula:

Cláusula lockeana: Toda apropiación es legítima si la apropiación de un objeto sin dueño no empeora la situación de los demás (1988, 176-177) ${ }^{8}$.

Es claro que si nadie encuentra un perjuicio al realizarse una apropiación por otro individuo, no habría razón para que dicha apropiación pueda ponerse en tela de juicio. Pero Nozick considera que dicha cláusula es demasiado fuerte, pues hace imposible la apropiación. Hay un sentido claro en el hecho de que todos los demás individuos en un estado de naturaleza experimentan un perjuicio al no poder disponer del bien apropiado; el perjuicio, sin importar su gravedad, está presente ya sea en el momento de realizarse la apropiación o en el futuro $(1988,177)$. Por dicho motivo, Nozick propone la siguiente variación más débil de la cláusula lockeana:

Cláusula de Nozick: "Toda apropiación es legítima si y solo si nadie tiene alguna razón para preferir que permanezca en uso general" (Cohen 1995, 76; la traducción es mía) 9 .

La idea del principio de Nozick es sostener que si bien puede existir un perjuicio al momento de realizarse la apropiación, el hecho de que dicha apropiación repercuta positivamente en los demás compensa dicho perjuicio (Nozick 1988, 178). La evaluación de dicha compensación tiene que tomar en cuenta dos posibles escenarios: uno en el que la apropiación tiene lugar y otro donde esta no ocurre. Para que un individuo considere la apropiación de un determinado bien como ilegítima, este debe considerar preferible que dicho bien se conserve en estado de naturaleza. Lo señalado

8 Nozick basa esta cláusula en la afirmación de Locke respecto a que uno tiene derecho a un bien "al menos cuando queden todavía suficientes bienes comunes para los demás" (Locke 2006, 34).

9 Esta reformulación es atribuida por Cohen a Nozick, quien se refiere a la misma como una variante más débil de la cláusula de Locke. 
previamente es discutible, pues toda persona puede verse a sí misma como potencial beneficiario del bien si este no fuera poseído por el que originalmente se apropió de él. Ante ello, el libertario puede responder que todo individuo que prefiriera que dicha propiedad pase a sus manos, tampoco podría encontrar dicha propiedad justificada. De ese modo, se confirma que la determinación del perjuicio solo se realice entre el escenario en que dicho bien pase a ser de uso privado o se mantenga sin dueño (Cohen 1995, 78).

Para Cohen, el hecho de que se tenga que elegir entre la apropiación privada o la ausencia de la misma es en realidad un falso dilema. Según Cohen, dado que Nozick parte de asumir implícitamente un escenario en el que la otra persona podría estar de acuerdo, es plausible contemplar una tercera alternativa en la que dicho bien se convierta en propiedad colectiva ${ }^{10}$. Es completamente razonable que las personas puedan considerar preferible una sociedad donde la propiedad pueda ser disfrutada de un modo en el que todos puedan estar de acuerdo y los usos estén determinados por lo que la comunidad cree que maximiza el bienestar de todos en la sociedad (Cohen 1995, 83) $)^{11}$.

Una vez puesta en cuestión la teoría de la apropiación de Nozick, Cohen pasa a poner en duda el papel que la propiedad de uno mismo puede jugar al defender la existencia de una sociedad capitalista de Estado mínimo. Para entender adecuadamente el caso vale la pena recordar el famoso ejemplo de Wilt Chamberlain:

Ahora bien, supongamos que Wilt Chamberlain se encuentra en gran demanda por parte de los equipos de baloncesto, por ser una gran atracción de taquilla. (Supóngase también que los contratos duran sólo por un año y que los jugadores son agentes libres). Wilt Chamberlain

10 De hecho, el propio Nozick contempla este escenario al final de su reflexión sobre la teoría de la adquisición, como una deuda explicativa que tendrían los defensores de la legitimidad de la propiedad colectiva, pero no la considera al formular su análisis respecto de la superioridad de la privatización sobre la permanencia del bien en uso común $(1988,178)$.

11 Dicha forma de entender la propiedad permite comprender el sistema dominial del subsuelo, que establece que los recursos encontrados en este pertenecen al Estado. En contraste con el sistema fundiario que no establece la separación entre la propiedad del suelo y subsuelo, permitiendo la propiedad privada de los recursos del subsuelo (Gutiérrez, 2010). 
firma la siguiente clase de contrato con un equipo: en cada juego en que su equipo sea local, veinticinco centavos del precio de cada boleto de entrada serán para él (ignoramos la cuestión de si está "saqueando" a los propietarios, dejando que se cuiden solos). La temporada comienza, la gente alegremente asiste a los juegos de su equipo; las personas compran sus boletos depositando, cada vez, veinticinco centavos del precio de entrada en una caja especial que tiene el nombre de Chamberlain. Las personas están entusiasmadas viéndolo jugar; para ellos vale el precio total de entrada. Supongamos que en una temporada, un millón de personas asisten a los juegos del equipo local y que Wilt Chamberlain termina con 250 mil dólares, suma mucho mayor que el ingreso promedio e incluso mayor que el de ningún otro. ¿Tiene derecho a este ingreso? (Nozick 1988, 163).

Nozick pretende resaltar que, dadas las capacidades de una persona, esta puede valerse de las mismas para obtener recursos de modo que pueden surgir grandes desigualdades legítimas. En el ejemplo anterior, no hay necesidad de brindar una justificación de la propiedad privada sobre recursos externos, solo basta tener en consideración el hecho de que la persona realiza acciones que tienen como consecuencia la obtención de un beneficio, ya sea porque se lo apropió del mundo u otros lo hayan transferido a él. El papel que juega la propiedad de uno mismo es brindar una justificación de la desigualdad, como el resultado inevitable de la protección del derecho que tiene toda persona al resultado del empleo de sus propias capacidades, y que nadie puede arrebatarle sin su consentimiento $(1988,166)$.

Para entender mejor el argumento, asúmase que en un momento determinado se decide corregir el problema de la desigualdad y de ese modo se decide distribuir los bienes existentes entre todos los habitantes de la sociedad. Al hacer esto, la persona que defiende que la propiedad privada es ilegítima ya no tendría motivos para cuestionarla pues esta acaba de ser distribuida de un modo equitativo entre todos en la sociedad; de modo que uno acepta que la sociedad se halla en una condición que calificaría sin problemas de justa. Ahora bien, si es cierto que dicha sociedad es una sociedad justa, no tenemos razones para objetar el cambio si tenemos intercambios voluntarios que terminan rompiendo con dicha igualdad alcanzada, pues el punto de partida fue justo y el procedimiento también lo fue (Nozick 1988, 154-155). En el caso de Wilt Chamberlain, si todos deciden voluntariamente 
pagarle un monto de dinero para verlo jugar, entonces no hay razón para objetar el resultado, que es el surgimiento de la desigualdad.

Hay dos formas de atacar el razonamiento de Nozick. La primera es sostener que la sociedad capitalista es el resultado de una acumulación primitiva que tiene en su base injusticias ${ }^{12}$. Por dicho motivo, el ejemplo de Nozick no es relevante para entender los problemas del sistema capitalista en un mundo donde la génesis del mismo está marcada por la injusticia. No creo que esta forma de refutar a Nozick sea suficiente, ya que su teoría contempla la compensación y corrección de injusticias pasadas (claro que ese aspecto de su teoría es ignorado por sus seguidores de derecha) (1988, 176). De darse dichas compensaciones por las injusticias pasadas y establecerse una sociedad fundada en la igualdad de todos los bienes materiales, esta eventualmente daría paso al surgimiento de la desigualdad (a menos que se prohíban ciertos tipos de uso que la gente puede tener sobre su propiedad), que permite, entre otras cosas, la posibilidad de la aparición de la propiedad privada de los medios de producción $(1988,175)$.

La segunda forma de atacar el razonamiento de Nozick es justamente desbaratar el valor que la propiedad de uno mismo pueda tener para legitimar un sistema capitalista de Estado mínimo. Para ello, Cohen procederá estableciendo un escenario en el que hay dos individuos que habitan un mundo compartido. Ahora, retomando la idea presente en el ejemplo de Wilt Chamberlain, uno podría postular la presencia de dos principios que regirán para ambos individuos: el principio de igualdad y el principio de

12 La siguiente cita de Srnicek y Williams expresa claramente dicha perspectiva:"En las sociedades precapitalistas, el trabajo era necesario, pero la gente tenía un acceso compartido a la tierra, a la agricultura de subsistencia y a los medios necesarios de supervivencia. Los campesinos eran pobres pero autosuficientes y la supervivencia no dependía de que se trabajara para alguien más. El capitalismo cambió todo. Mediante el proceso conocido como «acumulación primitiva», los trabajadores precapitalistas se vieron desarraigados de sus tierras y despojados de sus medios de subsistencia. Los campesinos lucharon contra esta situación y continuaron sobreviviendo en los márgenes del incipiente mundo capitalista, que, con el tiempo, cobró una fuerza violenta y adoptó nuevos y severos sistemas legales para imponer el trabajo remunerado a la población. En otras palabras, debía convertirse a los campesinos en proletariado, esta nueva figura del proletariado se definió por su falta de acceso a los medios de producción o subsistencia y por su necesidad del trabajo remunerado para sobrevivir" (Srnicek y Williams, $2017,125-126)$. Para la aproximación más famosa al tema de la acumulación originaria del capital también se puede revisar el capítulo vigésimo cuarto de El capital (Marx, 1978). 
propiedad de uno mismo. Hay dos maneras de entender el principio de igualdad: por un lado, una en la que todas las personas gocen de una porción equitativa del total de los bienes del mundo; y, por otro lado, otra en la que la propiedad pertenezca a ambos sujetos en conjunto (Cohen 1995, $15,93,103)$.

Los individuos que habitan dicho mundo, a los que Cohen llamará Able e Infirm, tienen las siguientes características: por un lado, Able es alguien completamente capaz de poder trabajar y producir los bienes del mundo, de modo que haya suficiente no solo para él, sino también para Infirm. Por otro lado, Infirm es un sujeto enfermizo con capacidades productivas limitadas, que de no recibir parte de lo que Able pueda producir, estará condenado a morir eventualmente $(1995,94)$. Bajo estas consideraciones, tómese dos posibles formas de organización social. Una en la que se toma el principio de igualdad como un principio de igual división de bienes correspondiente a la primera formulación del principio de igualdad; y otra en la que se toma dicho principio como uno donde la propiedad pertenece a ambos en conjunto, correspondiente a la segunda formulación del principio de igualdad. La característica clave del segundo escenario es que al tratarse de una propiedad colectiva, todo aquello que quiera hacer Able con los bienes disponibles requiere del consentimiento de Infirm para ser hecho; mientras que en el primero, una vez se ha dado paso a la división, cada persona puede hacer con lo que tiene lo que crea pertinente sin tener que solicitar la autorización del otro.

Cohen señala lo siguiente a partir del anterior caso: en la primera forma de organización social, evidentemente el principio de propiedad de uno mismo se preserva, pero eventualmente el principio de igualdad se pierde, pues dado que Able tiene mayores capacidades productivas, puede proveerle a Infirm los bienes para su subsistencia a cambio de lo que Infirm posee, de modo tal que Infirm termine completamente desposeído (1995, 103-104). No hay manera de garantizar la igualdad en la división de bienes en dicho escenario y siempre ocurrirá que Able tendrá más que Infirm. Incluso si luego de un tiempo se decide volver a redistribuir el total de bienes existentes, la propiedad de uno mismo que existe en dicho contexto hará emerger eventualmente la desigualdad. De este modo, podemos decir 
que el principio de igualdad en su primera versión no es compatible con el principio de propiedad de uno mismo. La única manera de preservar la igualdad es vulnerando la propiedad de uno mismo $(1995,104)^{13}$.

En la segunda forma de organización social, tenemos el siguiente caso. Nada de lo que haga Able puede ser hecho sin que Infirm lo consienta, de modo que Infirm puede solicitar a Able que este, al trabajar o producir, brinde parte de lo que sin problemas puede obtener como excedente para la subsistencia de Infirm debido a su debilidad para garantizar su propio sustento. En este escenario, Cohen busca dejar claro que Able no es dueño completo de todo el resultado de sus acciones, pues en dicho contexto nada de lo que produce puede ser gozado del modo en el que unilateralmente prefiera $(1995,97-98)$. Podemos decir que este escenario puede garantizar la preservación de la igualdad, pero claramente la propiedad de uno mismo está siendo constantemente limitada ${ }^{14}$.

¿A qué viene dicha evaluación? Cohen señala que el motivo por el cual la propiedad de uno mismo está limitada en el segundo escenario es que Able no puede acceder a los medios de producción de manera unilateral, sino que necesita la autorización de Infirm para hacerlo. El hecho de necesitar la

13 En este escenario podría objetarse que Able no tiene por qué solidarizarse con la situación de Infirm, dado que, si bien los dotes naturales son arbitrarios, ello no tiene por qué implicar injusticia. Ante ello debe señalarse que: no es claro cómo una situación de la cual ninguno de los dos agentes es responsable puede poner a uno en una posición de dominio respecto al otro y no constituir un escenario de injusticia. La arbitrariedad del azar ha sido justamente un objeto clave en los análisis contemporáneos acerca de la justicia (Rawls, 1979). El considerar una situación arbitraria como justa resulta lo suficientemente contraintuitiva como para tomarla en serio sin un argumento a su favor. Por otro lado, en esta etapa del argumento solo se está evaluando la posibilidad de establecer la compatibilidad entre un principio de justicia y el principio de propiedad de uno mismo; no se está brindando una justificación de por qué se debe privilegiar el principio de igualdad por sobre el de propiedad de uno mismo.

14 Es importante señalar que cualquier otro escenario pensable respecto a dicho régimen de propiedad solo es relevante si puede lograr una reconciliación plena del principio de igualdad (en su segunda formulación) y el principio de propiedad de uno mismo. Considerar un escenario de acuerdos mínimos no tiene sentido, pues Able, al verse obligado a tener que realizar cualquier acuerdo con Infirm para poder aprovechar los recursos del mundo, ya encuentra limitada la propiedad que tiene sobre sí mismo. El punto del ejemplo es mostrar que Able en este escenario está impedido de actuar de modo unilateral, por lo cual carece de auto propiedad. Por otro lado, tampoco sería relevante considerar la posible muerte natural de uno de los involucrados, pues no aporta nada al objetivo del argumento, que es demostrar la incompatibilidad del principio de igualdad y de propiedad de uno mismo. En ausencia de alguien más en el mundo, el principio de igualdad ya no tiene relevancia normativa. 
aceptación de Infirm para poder acceder a los bienes del mundo da lugar a sostener que Able carece o ve violado su derecho a la propiedad de uno mismo. De ese modo, Cohen pasa a sostener que el escenario donde la propiedad de uno mismo se halla bloqueada también puede encontrarse en una sociedad de propietarios privados de los medios de producción, escenario en donde un individuo no propietario está impedido de acceder a dichos medios a menos que suscriba un contrato de explotación laboral $(1995,100)$. Esto último es clave porque Nozick señala que un individuo en una sociedad que ha llegado a un mundo donde todo lo existente ya ha sido apropiado (sea cual sea el procedimiento legítimo que pueda existir) no es menos libre si su única alternativa para subsistir es trabajar para el capitalista y asalariarse:

$Z$ se enfrenta a la alternativa de trabajar o morirse de hambre; las selecciones y acciones de todos los demás no se suman para dar a $\mathrm{Z}$ alguna otra opción. (Él puede tener varias opciones acerca de qué trabajo tomar) ¿Escoge $Z$ trabajar voluntariamente? (¿Lo hace en una isla desierta alguien que debe trabajar para sobrevivir?) $Z$ efectivamente decide en forma voluntaria si los otros individuos de A a Y, cada uno actúa voluntariamente y dentro del marco de sus derechos. (Nozick 1988, 255).

Obviamente una de las características clave de la explotación capitalista parte de darle a la persona la libertad de poder aceptar o no sus condiciones de explotación; el individuo Z puede elegir no trabajar y morirse de hambre, en el mismo sentido en el que Able puede negarse a trabajar para Infirm y elegir la muerte. Pero nótese que Nozick está concediendo en el ejemplo del individuo $Z$ que por muy restringidas que puedan estar sus alternativas, él sigue eligiendo de modo voluntario, por lo tanto, la propiedad de uno mismo se conserva en dicho escenario. Si lo anterior es verdad, entonces en el caso de Able también podemos pensar que por muy limitadas que puedan estar sus acciones, debido a la necesidad del consentimiento de Infirm, también sigue siendo dueño de sí mismo. Si el libertario no está de acuerdo con la propiedad conjunta del mundo porque limita la propiedad de uno mismo de Infirm, también debería estar en contra del capitalismo de Estado mínimo por que la propiedad de uno mismo de Z está igualmente limitada en él. Si el libertario acepta que $Z$ realmente tiene propiedad de uno mismo, entonces la propiedad de uno mismo está presente en un 
mundo de propiedad colectiva tanto como en uno de propiedad privada (Cohen 1995, 100-101).

Es de este modo que Cohen lleva a la propuesta de Nozick a un dilema: o bien la propiedad de uno mismo que él valora es meramente formal, completamente compatible con una sociedad gobernada por un principio de igualdad, o la propiedad de uno mismo que él valora es una concepción más sólida que, al estar ausente bajo el capitalismo de Estado mínimo, deja a este injustificado (Weinberg 1997, 303) ${ }^{15}$.

\section{§3. La crítica de Mack a la propuesta de Cohen}

Mucha tinta ha corrido acerca de este asunto; diferentes teóricos de la derecha libertaria dedicaron esfuerzos (infructuosos, a mi parecer) para tratar de atacar la propuesta de Cohen. Esta sección pretende abordar justamente las críticas de Eric Mack a la postura de Cohen. Lo primero a tener en cuenta es que el propio Mack no está ofreciendo una defensa completa de la teoría de Nozick, sino que su intención es ofrecer una defensa explícita de la propiedad de uno mismo, sobre todo del capitalismo de Estado mínimo que la promueve. Mack dedica la segunda parte de su artículo "Self-Ownership, Marxism, and Egalitarianism" a responder las críticas de Cohen.

Mack inicia aceptando que tanto el individuo $Z$ y Able carecen de propiedad de sí mismos, pero que ello no significa que el capitalismo de Estado mínimo esté condenado a replicar el caso del individuo $Z$, mientras que una sociedad gobernada por pautas de distribución igualitaria replica y generaliza el caso de Able en toda la sociedad (Mack 2002, 244). Para llevar a cabo su crítica, Mack inicia señalando que es necesario renunciar a una tesis de Nozick que es parte de lo que lo lleva a la trampa de Cohen, esto es,

15 Es interesante señalar que Justin Weinberg, identifica en la propuesta de Cohen una alternativa adicional, al señalar que el libertario puede identificar que el individuo $Z$, a diferencia de Able, tiene pequeños márgenes de decisión mayores (puede elegir para quién trabajar, dónde vivir, etc.). Para Weinberg, dicha estrategia procede a defender la propiedad de uno mismo en $Z$ apelando a una noción de autonomía que, de volverse fundamental, legitima la posibilidad de impuestos redistributivos para materializarla en todos los individuos $(1997,334)$. 
la idea de que si se tiene una situación inicial justa y pasos justos, se llega a un resultado justo $(2002,244-245)$. Sobre este asunto, Cohen ya se había pronunciado críticamente en Self-Ownership, Freedom and Equality (1995, 44), y Mack, ante ello, ofrece una cláusula modificada de propiedad de uno mismo que puede rectificar escenarios injustos surgidos de una sociedad justa por medio de pasos justos:

Cláusula de propiedad de uno mismo: Una persona será dueña de sus talentos y energías, siempre y cuando estos talentos y energías también se entiendan como "poderes interactivos con el mundo" (Mack 1995, 186).

Mack hace un cambio importante a la formulación de la cláusula de propiedad de uno mismo al añadirle un componente relacional ausente en la caracterización original identificada en la obra de Nozick y desmantelada por Cohen. La idea de Mack es sostener que no solo hay una violación a la propiedad de uno mismo cuando se apuñala a alguien con un cuchillo, a pesar de que la persona que posee el cuchillo sea propietaria legítima de dicho objeto, sino que también podemos encontrar un daño a la propiedad de uno mismo cuando se bloquea las interacciones que una persona puede tener con el mundo $(2002,246)$. Para explicar esto, Mack pone dos ejemplos: en el primer ejemplo nos propone el caso de dos individuos: Sally y Harry. Asumamos que existe una manera legítima de poder apropiarse de las cosas del mundo de modo que un día, mientras Sally duerme, Harry decide construir una jaula alrededor de ella con un material maleable que él mismo ha fabricado y posee legítimamente. Al despertar, Sally se da cuenta de que está atrapada y, al intentar salir, es increpada por Harry, quien señala que no tiene derecho a poder tocar su propiedad sin su consentimiento. Es claro que en este caso, la situación de Sally se ha visto empeorada por las acciones y la propiedad de Harry, de modo que el derecho de propiedad de Harry se ve revocado en dicha circunstancia y Sally legítimamente puede destruir la jaula $(2002,246)$.

Ahora tómese otro caso en el que Harry no construye una jaula alrededor de Sally, sino que, por el contrario, cubre todo el mundo que rodea a Sally con el material maleable con el que diseñó la jaula, de modo que ella se 
encuentra imposibilitada de poder relacionarse con el mundo, pues Harry proclama que no tiene derecho a poner sus manos sobre el plástico que él ha creado sin su consentimiento. En dicho escenario, también Sally puede reclamar que se ha vulnerado la cláusula de propiedad de uno mismo al restringirle su capacidad interactiva con el mundo. Es importante tener claro que la cláusula de propiedad de uno mismo debe tener como elemento constitutivo que la persona pueda relacionarse de modo directo y sin restricción con las cosas del mundo $(2002,246)$.

De los dos ejemplos previos Mack pasa a uno tercero en el que pretende sostener que hay un escenario donde la propiedad de un bien no afecta la cláusula de propiedad de uno mismo. Supongamos que Harry ha fabricado una herramienta que emplea a escondidas de Sally y que siempre que ella se va a topar con la misma, Harry logra sacarla de su alcance, de modo que Sally no puede reclamar que la misma afecta sus capacidades interactivas con el mundo. En ese sentido, este tipo de propiedad no viola la cláusula de propiedad de uno mismo $(2002,246-247)$.

Mack necesita el caso anterior para dar lugar a su siguiente ejemplo. Imaginemos que Harry decide ya no ocultarle a Sally la herramienta, sino que decide vendérsela. Sally no puede señalar dicha práctica como algo que vulnere la cláusula de propiedad de uno mismo, pues como se vio en el ejemplo anterior, el no tener acceso a la misma no afectaba su capacidad de interactuar con el mundo $(2002,247)$. Ahora bien, Mack concede que puede que dicho objeto, al ser de conocimiento de Sally, resulte muy útil para poder realizar un trabajo que antes era muy pesado. Frente a ello, Harry puede decidir vendérselo a Sally a cambio de lo que desee. Sally no puede señalar que Harry está vulnerando la cláusula de propiedad de uno mismo, sino que, por el contrario, está amplificando las capacidades interactivas sobre el mundo al ofrecerlo al intercambio $(2002,247)$.

Claramente hay una movida discutible en el ejemplo que ha de ser examinada, pero vale la pena realizar la exposición completa del caso de Mack para dar paso a la evaluación de sus límites. La conclusión a la que pretende llegar es que la persona aún tiene posibilidad de acceder a dichos bienes, claro está, bajo ciertas condiciones puestas por el propietario. Ahora 
bien, Mack pasa de esta exposición a desarrollar justificaciones de tipo consecuencialista para darle peso a la idea de que la privatización genera beneficios de acceso a más bienes, punto que si bien no es menor, para este artículo es una disputa que tiene una dimensión de análisis diferente $(2002,248)^{16}$. A fin de cuentas, muy al margen de si es cierto o no que un sistema de privatizaciones funciona mejor que uno de propiedad colectiva, el punto al que quiere llegar Mack es que el capitalismo de Estado mínimo es moralmente objetable si y solo si el sistema de propiedad no lleva a Sally a ocupar la posición del individuo Z del que Nozick hablaba.

Mack concede que un problema fundamental del capitalismo de Estado mínimo es la posibilidad del surgimiento de monopolios que generan dificultades de acceso a diferentes bienes $(2002,249)$. El individuo $Z$ será víctima de un sistema que restringe de manera profunda el acceso al mundo para las personas. En ese sentido, es legítimo emplear medidas que eviten los monopolios comerciales, pues estos vulnerarán la cláusula de propiedad de uno mismo propuesta por Mack $(2002,250)$. Si se logran establecer medidas para controlar y regular los monopolios, entonces hay una manera legítima en la cual el capitalismo de Estado mínimo puede seguir subsistiendo ${ }^{17}$.

Mack sostiene que si bien el problema de la existencia de monopolios puede acontecer en un régimen de propiedad privada de Estado mínimo, dicho problema está presente de modo constante en un régimen de propiedad colectiva del mundo $(2002,250)$. Es decir, en escenarios como en el ejemplo de Able e Infirm. A criterio de Mack, todo régimen de propiedad colectiva implica necesariamente la violación de la cláusula de propiedad de uno mismo. En ese sentido, en una sociedad donde rija un principio de igualdad, como el descrito en el segundo escenario de Cohen, hay siempre una vulneración constante de la cláusula de propiedad de uno mismo; cosa

16 El punto fuerte de una teoría libertaria es lograr una justificación de la propiedad privada basada en derechos y no en consecuencias. Apelar a las buenas consecuencias de la propiedad privada corresponde a una línea de argumentación que pone serias dudas en las razones para preferir un capitalismo de Estado mínimo a una sociedad liberal gobernada por el principio de la diferencia (Rawls 1979).

17 Téngase en cuenta que, para Mack, la regulación de monopolios no implica la suscripción de ningún principio de redistribución en nombre de la igualdad. 
que en el capitalismo de Estado mínimo puede ocurrir, pero puede ser corregido. En el caso de una sociedad donde la propiedad sea colectiva, la restricción de la propiedad de uno mismo es insuperable. Mack procede a señalar que, si desaprobamos el escenario del individuo $Z$, entonces no se puede defender un régimen de propiedad colectiva (donde todos viven en dicha condición), mientras que sí es posible aprobar un régimen de propiedad privada adecuadamente regulado $(2002,251)$. Así, Mack voltea el caso de Cohen y, tomando en este caso la clara desaprobación del enfoque igualitarista del escenario del individuo $Z$, pretende llevar a su expositor a tener que rechazar el igualitarismo de propiedad colectiva, y preferir un capitalismo de Estado mínimo libre de monopolios.

\section{§4. Defensa del enfoque igualitarista de Cohen}

Para responder a la crítica de Mack a Cohen, primero tenemos que determinar el alcance de la pertinencia de sus consideraciones sobre la sociedad capitalista donde se carece de monopolios. La idea subyacente a su crítica de Cohen es que, si se restringen los monopolios, no se viola la cláusula de propiedad de uno mismo. Para poder derribar dicha objeción procederé mediante tres críticas: La primera crítica buscará defender que la cláusula de propiedad de uno mismo, por un lado, se preserva mejor en una sociedad de propiedad colectiva, y, por otro lado, que no cumple con legitimar el surgimiento del Estado mínimo o no logra evitar realmente el escenario del individuo Z. La segunda crítica buscará mostrar que la cláusula de propiedad de uno mismo no tiene éxito al impugnar la legitimidad de la redistribución. Por último, la tercera crítica buscará mostrar que Mack se equivoca al tratar la presencia de monopolios como una característica estructural de los regímenes de propiedad colectiva. Si las tres críticas anteriores tienen éxito, no solo habré desarticulado la crítica de Mack, sino que también ofreceré un argumento a favor de la legitimidad de la propiedad colectiva y el igualitarismo.

Para iniciar con la primera crítica es importante recordar que, para Cohen, la propiedad de uno mismo estaría ausente toda vez que la segunda formulación del principio de igualdad lograba preservarse. De ese modo, todos 
los miembros deben alcanzar un acuerdo respecto a los usos permitidos de la propiedad colectiva. Por su parte, en el capitalismo de Estado mínimo, la propiedad privada obligaba a que el acceso a los bienes tenga que estar mediado por el mutuo acuerdo entre poseedores y desposeídos. Notemos que en el proceso de deliberación propio de la propiedad colectiva, el acuerdo que las partes pueden alcanzar puede resultar lo más ventajoso para ambos sujetos, mientras que en el escenario de propiedad privada, siempre hay alguien que ostenta una posición de ventaja relativa. A lo anterior, debe añadirse que la existencia de propiedad colectiva no implica la ausencia de uso de bienes, ya que estos, bajo ciertas condiciones decididas colectivamente, se hacen accesibles a los miembros de la sociedad. Si lo anterior ocurre, entonces las capacidades interactivas propias de los poderes y capacidades de los habitantes no se ven reducidas, sino que incluso pueden verse amplificadas. En el caso del capitalismo de Estado mínimo está presente el riesgo constante a la privación unilateral del acceso a ciertos bienes bajo condiciones poco preferibles para los desposeídos.

A esto Mack podría responder que las condiciones de acceso limitadas se deben a la existencia de monopolios que la cláusula de propiedad de uno mismo puede regular. ¿Cómo ocurriría esta regulación respecto a medios de producción como la tierra? Mack señala que el motivo por el cual $Z$ esta privado de acceso a los medios de producción es la ausencia de competencia de mercado (2002, 249); es decir, el motivo por el cual Z carece de propiedad de sí mismo, es que no hay suficientes capitalistas compitiendo por contratarlo ${ }^{18}$. Pero el hecho de que alguien más te pueda ofrecer un contrato de trabajo, no significa que no sigas privado del acceso a los medios de producción, lo único que cambia en este nuevo escenario es que las condiciones para acceder a dichos medios de producción son menos desfavorables que las existentes en un capitalismo con monopolios. $\mathrm{Si}$ al final lo que importa es que las condiciones de acceso a los medios de producción sean menos desfavorables, la propiedad colectiva parece poder garantizar el mismo resultado.

18 Conforme haya más propietarios diferentes sobre los medios de producción en competencia, la situación de $Z$ mejorará; esto debido a que puede acceder a trabajar para un capitalista no por temor a morirse de hambre, sino porque la competencia lleva a que la demanda de mano de obra sea lo suficientemente alta para que su salario sea lo que lo motive a elegir. 
A lo anterior vale la pena añadir que la estructura legal de una sociedad capitalista de Estado mínimo se asemeja más al segundo escenario de Harry y Sally descrito por Mack ${ }^{19}$, que al tercero. Pues toda persona que llega a un mundo de propiedad privada de los medios de producción, ya encuentra sus capacidades interactivas con el mundo bloqueadas por el marco legal vigente. De ese modo, no es clara la diferencia estructural entre el capitalismo de Estado mínimo carente de monopolios, pero con propiedad privada de los medios de producción, y una sociedad de propiedad colectiva. Por último, no es claro cómo a partir de un caso que aparentemente sí cumple la cláusula de propiedad de uno mismo (el de la herramienta de Harry) ${ }^{20}$ se pretende justificar el surgimiento de la propiedad privada de medios de producción, que, por lo expuesto, vulnera la cláusula que el propio Mack establece.

Pasemos a la segunda crítica. Mack dedica parte de su artículo a defender que la propiedad de uno mismo por sí misma es capaz de ofrecer un argumento en contra del igualitarismo que no depende del proceso de apropiación de bienes externos. Cada vez que se establezca una pauta distributiva, se obtiene trabajo gratuito de algún otro individuo (2002, 253). Mack rescata la idea de Nozick de que las imposiciones tributarias en favor de la redistribución son formas veladas de esclavitud, violándose claramente la propiedad de uno mismo $(2002,253)$. Esta aproximación crítica no parte de la cláusula de propiedad de uno mismo, y solo se queda con la formulación original de Nozick. Lo anterior es importante para explicar que el problema identificado con las pautas distributivas es que los individuos

19 Aquel en el que el mundo era recubierto por el material maleable que justamente violaba la cláusula de propiedad de uno mismo.

20 Muy al margen de la artificialidad del tercer caso de Mack, parece que ni siquiera puede este cumplir la cláusula de propiedad de uno mismo, y es que al ser una cláusula que habilita o no la propiedad, debería aplicarse en principio a las materias primas empleadas, ya sea para fabricar la herramienta, el material maleable o la jaula. Si Harry transforma un determinado material natural y luego se encarga de hacerlo inaccesible a Sally, parece que sí está interfiriendo con las capacidades interactivas con el mundo de Sally, pues se le impide interactuar con una parte del mundo que antes de la apropiación de Harry era accesible a Sally. Parece que la cláusula de propiedad de uno mismo solo podría cumplirse en caso de que aquel artefacto haya sido producido con parte del propio cuerpo de Harry. Creo que ningún libertario o igualitarista consideraría ese punto como una victoria o derrota relevante para su posición. 
se hacen acreedores a beneficios que no merecen por no ser frutos de su esfuerzo $(2002,254)$.

Para que el anterior argumento libertario tenga éxito, se necesita demostrar que hay una correlación entre esfuerzo y recompensa. En otras palabras, probar que el trabajo invertido por el individuo en su totalidad es la causa principal de los beneficios obtenidos ${ }^{21}$. Si los beneficios obtenidos se explican por elementos adicionales al trabajo invertido por el propietario, entonces no se estaría cometiendo una vulneración moral al redistribuirlos. John Christman elabora respecto de este caso un argumento elegante que podemos sintetizar del siguiente modo (1994, 92-93): Tememos a un sujeto $\mathrm{S1}$, que realiza una cantidad de esfuerzo E1, tal que obtiene el beneficio $\mathrm{B} 1$; por otro lado, tenemos al sujeto S2, que realiza una cantidad de esfuerzo E2, tal que obtiene el beneficio B2. El argumento de Nozick-Mack será correcto en caso se cumpla la siguiente condición: si B1 es mayor que B2, entonces E1 será mayor que E2. Lastimosamente en una sociedad de mercado con propiedad privada, lo anterior no se cumple. Para demostrar esto, usaré un ejemplo sencillo. Tenemos un CEO de una firma que gana 50 mil soles mensuales, mientras que tenemos a un obrero de construcción que gana 500 soles mensuales. Incluso aceptando que el CEO realiza mayor esfuerzo productivo que el obrero (cosa ya de por sí discutible), para merecer moralmente el total de los 50 mil, tendría que haber realizado 100 veces el esfuerzo realizado por el obrero en un mes. Claramente el esfuerzo del CEO no es la explicación de los 50 mil mensuales, sino otros factores como la división social del trabajo, en la cual él, por una cantidad amplia de factores variables, ocupa una posición privilegiada, así como la posición que ocupa su industria en el mercado, que por lo general genera dichas ganancias debido a las condiciones de competencia $(1994,93)$. La explicación de su riqueza trasciende el esfuerzo realizado, por lo que una pauta distributiva que redistribuya sus ingresos no grava necesariamente el esfuerzo de la

21 El argumento de la esclavitud parcial de Nozick-Mack, necesita, para funcionar, que alguien se haga acreedor del trabajo ajeno al momento de beneficiarse de alguna política redistributiva. Según ambos autores, esto ocurre al momento de quitarle ingresos a una persona A para dárselo a una persona B. Por lo cual, la totalidad del trabajo invertido debe ser la explicación de la totalidad de los ingresos de A. Basta que alguna parte de dichos ingresos no se deba al trabajo de la persona $A$ para que pueda redistribuirse sin vulnerar la propiedad de uno mismo. 
persona, sino principalmente los aspectos sociales que permitieron que su esfuerzo generara dichas ganancias $(1994,93)$. De ese modo, las pautas distributivas son compatibles con la cláusula de propiedad de uno mismo22. El libertario puede objetar que lo anterior solo ocurre en un capitalismo de Estado donde hay monopolios, por lo cual en un capitalismo de Estado carente de monopolios, se tendría pautas distributivas que sí gravarían el valor neto del trabajo que un individuo realiza. Hay dos problemas con esta respuesta. El primero es que mientras no se haya alcanzado el equilibrio entre oferta y demanda, el Estado puede legítimamente redistribuir todos los ingresos generados por las barreras de ingreso al mercado que tienen los competidores. El segundo problema es que en un capitalismo de Estado mínimo carente de monopolios, las desigualdades serían tan poco relevantes que no sería necesario establecer pautas distributivas. De hecho, el igualitarismo de la suerte de Cohen es completamente compatible con dicha propuesta al condenar "las desigualdades que se deben a la suerte más que a la elección $(2008,300)^{\prime 23}$.

Por último, evaluemos la idea de que los monopolios son un problema intrínseco de la propiedad colectiva, mientras que solo es un problema accidental para la propiedad privada. Es decir, mientras que en una puede superarse el problema, en el otro dicho problema subsiste estructuralmente. Lo anterior parece tomar como punto de partida el hecho de que para la existencia de un mercado competitivo es necesaria la propiedad privada, y que la propiedad colectiva es incompatible con el mercado. Ante esto debe señalarse que la institución del mercado es neutral respecto al régimen de propiedad. Autores como John Roemer justamente desarrollaron

22 Si el libertario objeta que la pauta puede establecerse de modo que no se vulnere lo que podría atribuirse como resultado del esfuerzo de S1, entonces se siguen dos consideraciones: primero, que es legítimo en principio gravar con impuestos 49500 soles; y segundo, que el argumento de la esclavitud permite establecer una diferencia entre lo que se merece y lo que se obtiene, cosa que la teoría retributiva de Nozick pretendía evitar.

23 Este escenario contempla la posibilidad de que dos individuos que realizan una tarea puedan obtener ingresos diferentes si es que el trabajo realizado por uno de ellos es mayor al realizado por el otro. Lo único que se necesita para rebatir el argumento de Mack es mostrar que el Estado tiene potestad de analizar si las diferencias en el ingreso son proporcionales al trabajo empleado y de no ser el caso, puede aplicar una pauta distributiva legítimamente. Para una aproximación a la propuesta igualitarista de Cohen, se puede revisar On the Currency of Egalitarian Justice (1989). 
un modelo de mercado competitivo completamente compatible con la propiedad colectiva $(1992,452)$. Se puede entonces evitar los monopolios sin tener que conservar la propiedad privada, por lo cual es posible evadir el cargo de que la propiedad colectiva implica una violación estructural y constante de la cláusula de propiedad de uno mismo. Es más, teóricamente, sociedades de mercado socialista carentes de propiedad privada de los medios de producción pueden cumplir de mejor manera la materialización de la cláusula de propiedad de uno mismo que Mack tanto se esfuerza en defender ${ }^{24}$, al tener como meta el destinar las ganancias obtenidas en el mercado no a permitir la acumulación del capital en pocas manos, sino a brindar a la población los recursos y bienes necesarios para alcanzar una vida más plena, es decir, a permitir que los individuos puedan emplear de mejor manera sus capacidades interactivas con el mundo.

\section{$\S 5$. Conclusión}

El presente trabajo ha logrado brindar una justificación detallada de cómo las críticas de Mack no solo fracasan en condenar el igualitarismo, sino que ofrecen las herramientas conceptuales para entender la superioridad normativa de una sociedad carente de propiedad privada. Si asumimos la variación de la cláusula de propiedad de uno mismo como Mack la ha planteado, se logra tener un principio más fuerte que no excluye el principio de igualdad. Es importante poder ofrecer una respuesta a estos argumentos de naturaleza formal, pues el compromiso con la igualdad debe poder ser capaz de salir exitoso ante el escrutinio de argumentos formales de principios que buscan neutralizar el papel que pueda jugar la historia del capitalismo en su impugnación. Si somos capaces de criticar el capitalismo en el mejor escenario posible y partiendo de las premisas y métodos de

24 Es importante mencionar que la propuesta de mercado socialista es reciente y no ha sido aplicada en lo términos sugeridos por Roemer en ningún país hasta el momento. Me limito a dar cuenta de la existencia de un modelo matemático de mercado socialista que goza de la solidez suficiente para reconciliar la propiedad pública y el mercado. Para una exposición rigurosa acerca del modelo de mercado socialista en relación a la eficiencia de Pareto y la distribución de bienes, revisar: A Public Ownership Resolution of the Tragedy of the Commons (Roemer, 1989). 
algunos de sus más acérrimos defensores, podemos consolidar nuestro compromiso con un futuro diferente.

Recibido: $30 / 06 / 2020$

Aceptado: 06/09/2020

\section{Bibliografía}

Brenkert, George G., 1998. Self-Ownership, Freedom, and Autonomy. The Journal of Ethics 2, (1), 27-55.

Christman, John, 1994. The Myth of Property: Toward an Egalitarian Theory of Ownership. Oxford: Oxford University Press.

Cohen, G. A., 1989. On the Currency of Egalitarian Justice. Ethics 99 (4), 906-944.

- 1995. Self-Ownership, Freedom, and Equality. Nueva York: Cambridge University Press.

- 1998. Once More into the Breach of Self-Ownership: Reply to Narveson and Brenkert. The Journal of Ethics 2 (1), 57-96.

- 2008. Rescuing Justice and Equality. Cambridge: Harvard University Press

Gutiérrez, Carlos, 2010. La propiedad minera. Revista del Instituto de Investigaciones FIGMMG 13 (25), 42-48.

Locke, John, 2006. Segundo tratado sobre el gobierno civil: un ensayo acerca del verdadero origen, alcance y fin del gobierno civil. Madrid: Tecnos.

Mack, Eric, 1995. The Self-Ownership Proviso: A New and Improved Lockean Proviso. Social Philosophy and Policy 12 (1), 186-218.

- 2002. Self-Ownership, Marxism, and Egalitarianism. Part II: Challenges to the Self- Ownership Thesis. Politics, Philosophy and Economics 1 (2), 237-276.

Marx, Karl, 1978. El capital: Crítica de la Economía Política. Barcelona: Grijalbo.

Narveson, Jan, 1998. Libertarianism vs. Marxism: Reflections on G. A. Cohen's SelfOwnership, Freedom and Equality. The Journal of Ethics 2 (1), 1-26.

Nozick, Robert, 1988. Anarquía, Estado y utopía. México, D.F.: Fondo de Cultura Económica.

Rawls, John, 1979. Teoría de la justicia. México, D.F.: Fondo de Cultura Económica.

Roemer, John, 1989. A Public Ownership Resolution of the Tragedy of the Commons. Social Philosophy and Policy 6 (2), 74-92.

- 1992. The Morality and Efficiency of Market Socialism. Ethics 102 (3), 448-464. 
Rousseau, Jean Jacques, 2012. Discurso sobre el origen y los fundamentos de la desigualdad entre los hombres. Madrid: Alianza.

Srnicek, Nick y Alex Williams, 2017. Inventar el futuro: Postcapitalismo y un mundo sin trabajo, Barcelona: Malpaso.

Weinberg, Justin, 1997. Freedom, Self-Ownership, and Libertarian Philosophical Diaspora. Critical Review 11 (3), 323-344. 